\title{
Adult height is not associated with the risk of stomach cancer in a meta-analysis
}

\author{
Min Seok Seo ${ }^{1,2 \#}$, Dong Kyun Park ${ }^{3 \#}$, In Cheol Hwang ${ }^{4}$, Jae-Yong Shim ${ }^{2}$, Hong Yup Ahn \\ ${ }^{1}$ Department of Family Medicine, Incheon St. Mary's Hospital, Seoul, Republic of Korea; ${ }^{2}$ Yonsei University Graduate School of Medicine, Seoul, \\ Republic of Korea; ${ }^{3}$ Division of Gastroenterology, Department of Internal Medicine, ${ }^{4}$ Department of Family Medicine, Gil Medical Center, Gachon \\ University College of Medicine, Incheon, Republic of Korea; ${ }^{5}$ Department of Statistics, Dongguk University, Seoul, Republic of Korea \\ Contributions: (I) Conception and design: IC Hwang; (II) Administrative support: DK Park; (III) Provision of study materials or patients: None; (IV) \\ Collection and assembly of data: MS Seo, DK Park, IC Hwang; (V) Data analysis and interpretation: HY Ahn, JY Shim; (VI) Manuscript writing: All \\ authors; (VII) Final approval of manuscript: All authors. \\ \#These authors contributed equally to this work. \\ Correspondence to: In Cheol Hwang, MD, MPH, PhD. 1198 Guwol-dong, Namdong-gu, Incheon 405-760, Republic of Korea. \\ Email: spfe0211@gmail.com.
}

\begin{abstract}
Background: Adult height has been suggested as a biomarker for a wide range of diseases. However, there are epidemiologic inconsistencies regarding the association between adult height and stomach cancer risk.

Methods: We retrieved PubMed, EMBASE and Cochrane library databases to identify relevant studies assessing the relationship between height and risk of stomach cancer, published from inception to June 4, 2019. We pooled effect sizes for 5-cm height increments using a random-effect model and obtained the cumulative relative risk (RR) and $95 \%$ confidence interval (CI). Additionally, we performed subgroup investigation with sensitivity analysis and tested for publication bias using the Begg rank correlation test.

Results: We analyzed 11 studies involving 137,451 cases. The summary of effect size (95\% CI) of stomach cancer for a 5 -cm-increase in adult height was 0.99 (0.95-1.02). A "leave-one-out" sensitivity analysis indicated that the heterogeneity decreased by a half and the result showed significance (RR, 0.972; 95\% CI, 0.948-0.997). Subgroup analyses found no significant associations, with one exception. The exception also depended entirely on one study. We found no significant publication bias ( $\mathrm{P}=0.276)$.
\end{abstract}

Conclusions: Height is not associated with increased stomach cancer risk. Epidemiologic studies of potential confounders are needed to clarify the association.

Keywords: Height; stomach cancer; meta-analysis

Submitted Apr 27, 2020. Accepted for publication Jul 14, 2020.

doi: 10.21037/jgo-20-199

View this article at: http://dx.doi.org/10.21037/jgo-20-199

\section{Introduction}

Stomach cancer is one of common cancers and leading causes of cancer-related death worldwide, responsible for more than one million incident cases and an estimated 783,000 deaths in 2018 (1). Multiple factors have a role in the etiology of stomach cancer. Some of them (e.g., age, sex, ethnicity, and genetic factors) are not modifiable, whereas nutritional and behavioral factors potentially are (2). Nonmodifiable factors are not preventable but identifying them would be helpful to design effective screening programs.

Adult height is an indicator of the interplay between genetics and various environmental exposures during childhood, such as fetal, nutritional, socioeconomic, and psychological circumstances (3). Height is related to the risk of mortality and major diseases such as cancers and cardiovascular diseases $(4,5)$. Taller adults are reported to have increased risk for overall cancer and several common cancers. However, findings regarding height and stomach cancer are inconsistent. 
Because height range is usually narrow and large numbers of events are needed to reliably estimate risk, a pooled analysis is warranted. Notably, many studies relevant to this question were obscured by titles that emphasized other cancers or total cancers. Thus, to clarify the association between height and risk of stomach cancer comprehensively, we performed a meta-analysis with rigorous search strategies. We present the following article in accordance with the PRISMA 2009 reporting checklist. Available at http://dx.doi.org/10.21037/jgo-20-199.

\section{Methods}

\section{Search strategy}

This meta-analysis followed the Meta-analyses Of Observational Studies in Epidemiology (MOOSE) guidelines (6). We used PubMed, EMBASE and Cochrane library databases to identify relevant studies published from inception to June 4, 2019 that investigated the association between adult height and incident stomach cancer. The following keywords were used to extract the articles: ("anthropometry" OR "body size" OR "height") AND ("cancer" OR "neoplasm" OR "carcinoma") AND "risk". No restrictions were applied for language. We also manually searched the reference lists of all related articles and reviews to identify undetected relevant studies.

\section{Selection and processing}

Two authors (MS Seo and DK Park) performed all processes independently and resolved disagreements through discussion. Studies were included if they met the following criteria: (I) reported an association of adult height with stomach cancer; (II) reported risk estimates for incident stomach cancer, including relative risks (RRs), odds ratios (ORs), or hazard ratios (HRs) with $95 \%$ confidence intervals (CIs). When duplicate records were present for the same population, we selected studies with the most informative reporting or the larger sample size.

The following variables were extracted from each study: the first author's name; publication year; country where the study was performed; study design; participants; number of stomach cancer cases; follow-up years; assessment of height; the fully adjusted estimate with the corresponding 95\% CI; and covariates adjusted for the analysis.

We used the Newcastle-Ottawa Scale (NOS) to assess the study quality and allowed a total of 9 points to summarize eight aspects (with 9 points representing the highest quality) (7). An NOS score $\geq 8$ was defined as "high quality".

\section{Statistical methods}

Pooled measure was calculated as the inverse-variance weighted mean of the logarithm of RR (95\% CI) for stomach cancer for a 5-cm-increase in height. We considered HRs or ORs equivalent to RRs (8). We unified the forms of estimate as an RR for a 5-cm-increase in height, to minimize variability in categorization across the studies. For studies that did not provide estimates per unit of height, we used the Greenland and Longnecker method, which requires the case numbers and person-years or noncases and RRs with variance estimates for at least three height groups (9). We computed subgroup estimates (e.g., sex-specific or site-specific estimates) before inclusion in the meta-analysis.

We performed statistical analyses using Stata v9.2 (Stata Corp, College Station, TX, USA). Heterogeneity was tested using $\mathrm{I}^{2}$ statistics: $\mathrm{I}^{2}>50 \%$ is considered a high heterogeneity (10). A random effects model was used if substantial heterogeneity was observed; otherwise, a fixed effects model was applied. We performed subgroup analyses according to sex, study design, ethnicity, height assessments, body mass index (BMI) adjustment, and study quality. We also performed a leave-one-out sensitivity analysis by excluding one study at a time to assess results stability and potential sources of heterogeneity (11). Visual inspection of funnel plots and the Begg rank correlation test were used to assess publication bias.

\section{Results}

\section{Search and characteristics}

A flowchart of the study selection procedure is shown in Figure 1. After a first screening of duplicate and nonrelevant articles by title and/or abstract, we selected 36 articles for further assessment and reading of the full text. After detailed evaluations, we identified 11 observational studies that met all criteria for this meta-analysis (12-22). Detailed information about the studies included is summarized in Table 1.

\section{Quantitative analysis}

The pooled RR was 0.99 (95\% CI, 0.95-1.02) with each 


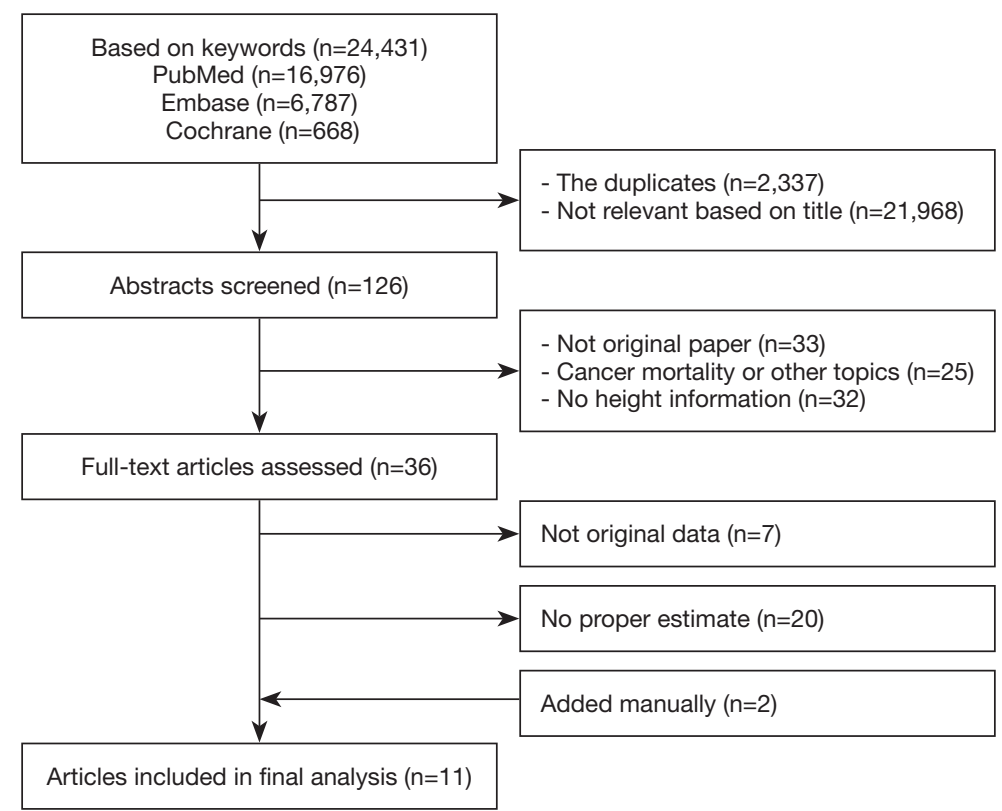

Figure 1 Flow diagram of the study selection process.

Table 1 Characteristics of studies on the effect of height on stomach cancer risk

\begin{tabular}{|c|c|c|c|c|c|c|c|c|}
\hline Study & Country & Design & Participants & Cases & $\begin{array}{l}\text { Follow-up } \\
\text { years }\end{array}$ & $\begin{array}{l}\text { Height } \\
\text { assessment }\end{array}$ & $\begin{array}{l}\text { Adjusted core variates } \\
\text { other than age and sex }\end{array}$ & Quality* \\
\hline Choi, 2019 & Korea & $\begin{array}{l}\text { Nested } \\
\text { case-control }\end{array}$ & $\begin{array}{l}22,809,722 \\
\text { adults }\end{array}$ & 131,682 & 5 & Measured & $\begin{array}{l}\text { BMI, smoking, alcohol, } \\
\text { exercise, diabetes }\end{array}$ & 9 \\
\hline Wiren, 2014 & $\begin{array}{l}\text { Austria, } \\
\text { Norway, } \\
\text { Sweden }\end{array}$ & $\begin{array}{l}\text { Prospective } \\
\text { (Me-Can cohort) }\end{array}$ & $\begin{array}{l}5,885,928 \\
\text { adults }\end{array}$ & 1,202 & 12.7 & Measured & None & 7 \\
\hline Kabat, 2013 & USA & $\begin{array}{l}\text { Prospective } \\
(\mathrm{WHI})\end{array}$ & $\begin{array}{l}144,701 \\
\text { women }\end{array}$ & 152 & 12 & Measured & BMI, smoking, alcohol, SES & 9 \\
\hline Green, 2011 & UK & Prospective & $\begin{array}{l}1,297,124 \\
\text { women }\end{array}$ & 1,177 & 9.4 & Self-reported & $\begin{array}{l}\text { BMI, smoking, alcohol, } \\
\text { exercise, SES, menarche age }\end{array}$ & 8 \\
\hline Merry, 2007 & $\begin{array}{l}\text { The } \\
\text { Netherlands }\end{array}$ & Prospective & 120,852 adults & 163 & 13.3 & Self-reported & BMI, smoking, SES & 8 \\
\hline Maclnnis, 2006 & Australia & Prospective & 41,295 adults & 98 & 11.3 & Measured & Exercise, SES & 7 \\
\hline Gunnell, 2003 & UK & Prospective & 2,393 men & 22 & 21 & Measured & BMI, smoking, SES & 8 \\
\hline Ji, 1997 & China & Case-control & 1,451 controls & 1,124 & NR & Self-reported & $\begin{array}{l}\text { Smoking, alcohol, SES, } \\
\text { chronic gastric diseases }\end{array}$ & 4 \\
\hline Hansson, 1994 & Sweden & Case-control & 679 controls & 338 & NR & Self-reported & BMI & 4 \\
\hline
\end{tabular}

*, based on the Newcastle-Ottawa Scale (0-9). Me-Can, Metabolic syndrome and Cancer project; NIH-AARP, National Institutes of Health-American Association of Retired Persons; WHI, Women's Health Initiative; BMI, body mass index; SES, socioeconomic status. 


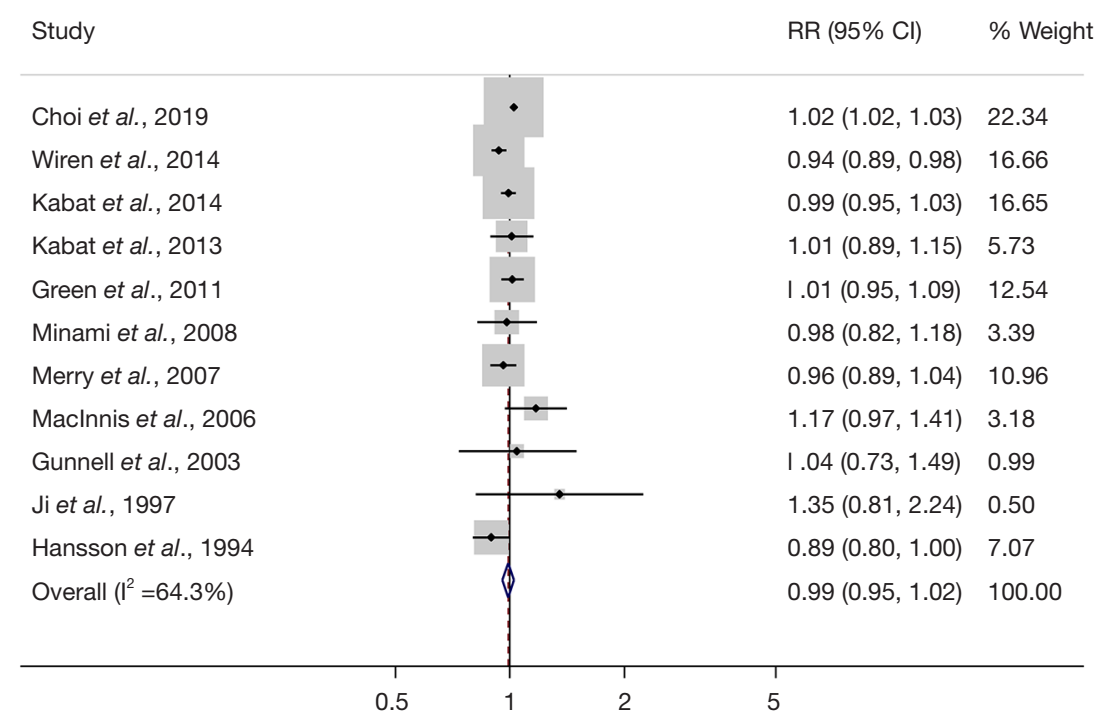

Figure 2 Forest plot of the association between height and stomach cancer risk. RR refers to the risk for developing stomach cancer per a 5 -cm increase in height. RR, relative risk; CI, confidence interval.

5-cm increase of adult height (Figure 2). Subgroup analysis and sensitivity analysis results are shown in Table 2. A "leave-one-out" sensitivity analysis-excluding Choi et al.'s study—revealed that the heterogeneity decreased by a half and the result showed significance (RR, 0.972; 95\% CI, 0.948-0.997). Overall, subgroup analysis findings depended on the study by Choi et al. In the analysis that found a significant positive result, the proportional weight of Choi et al.' study was more than $95 \%$. The funnel plot of the analysis of height and the risk of stomach cancer is shown in Figure 3 and a significant publication bias was not observed $(\mathrm{P}=0.276)$.

\section{Discussion}

In this pooled meta-analysis, we found no significant trend indicating an increased stomach cancer risk with increasing height. Rather, shorter Caucasians seemed to have higher risk for stomach cancer, and other subgroup analyses yielded no informative conclusions.

Stomach cancer has distinct epidemiological and clinical characteristics by the site (i.e., cardia vs. non-cardia) (23). Western countries have a higher proportion of and absolute increase in the incidence of cardia stomach cancer relative to non-cardia stomach cancer $(24,25)$. Obesity is a major risk factor for gastric cardia cancer, possibly through the association with gastroesophageal reflux disease (26). Short people have a higher BMI and higher obesity risk than taller people of the same weight. This is also true for noncardia gastric cancer, mainly caused by the infection with Helicobacter Pylori (H. pylori) (27). Chronic H. pylori infection is associated with poor growth in children (28), and thus this might explain the inverse association between height and stomach cancer (29). Notably, the NIH-AARP Diet and Health cohort reported that patients with non-cardia gastric cancer tend to be short in stature (30).

Adult height is determined both by genetics and early life exposures, and the outcomes of genetic potentials depend on environmental circumstances (3). Mechanisms have been proposed to explain the association between adult height and cancer (5). One explanation is that an insulinlike growth factor related to skeletal growth would also promote cell proliferation, inhibit apoptosis, and eventually lead to cancer $(31,32)$. Cellularity provides another potential explanation: taller people have larger organs composed of more individual cells, which translates to more opportunities for mutations that could lead to malignant transformation $(33,34)$. However, it is unclear if the above mechanisms contribute to stomach cancer risk.

Our meta-analysis has several limitations. First, the current findings are severely depended on only one study. In addition, lack of some information did not allow us to further address the association (e.g., the tallest group $v s$. the shortest group). Second, although some risk factors 
Table 2 Stomach cancer risk of a 5-cm increment in height

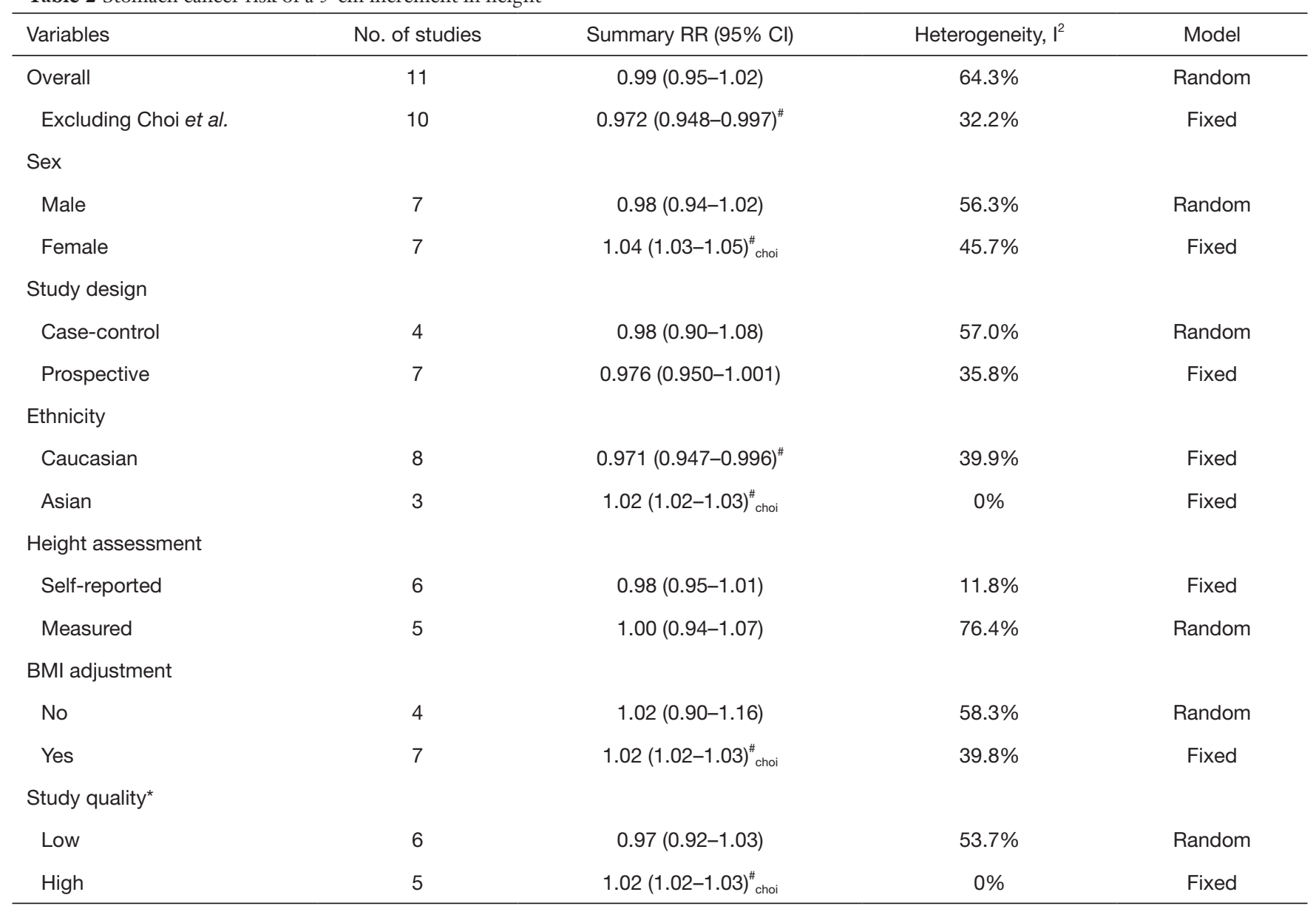

"Choi" in the subscripts refers to inclusion of the Choi et al. study; however, when it was excluded, the result was null. *, assessed using the Newcastle-Ottawa Scale score (<8 vs. $\geq 8)$. ", statistical significance shown in bold. RR, relative risk; Cl, confidence interval.

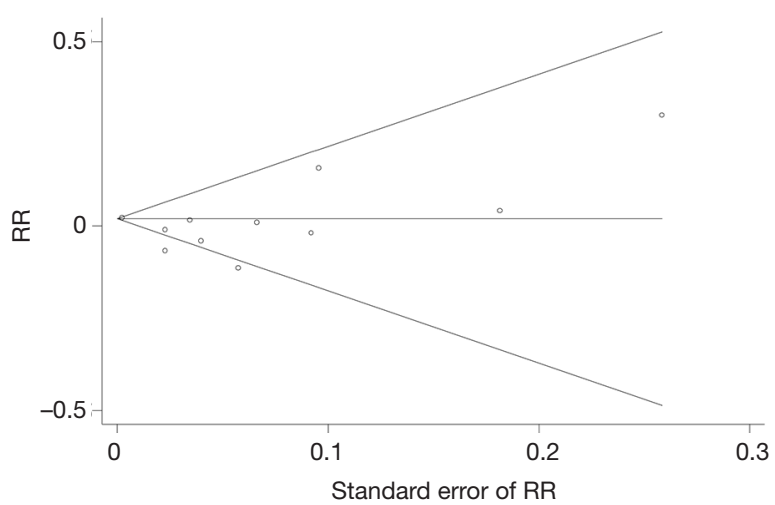

Figure 3 Funnel plot with $95 \%$ confidence limits for the incidence of stomach cancer among the included studies. RR, relative risk. were controlled, the possibility of unknown or residual confounding cannot be ruled out. The current evidence is flawed by a lack of data for certain factors, particularly the site of stomach cancer (i.e., cardia vs. non-cardia) and presence of $H$. pylori infection. Third, height assessments varied across the studies. Self-reporting to assess height may have led to overestimation of the actual heights, although high correlation has been reported between measured and self-reported one (35). Finally, the potential publication bias remains, despite no evidence of small study effects with the statistical tests in our study. It is still possible that many studies with null findings have been left unpublished.

In conclusion, this meta-analysis found no association between height and stomach cancer risk. Large-scale 
multicenter hospital-based studies with detailed clinical information are warranted to elucidate subsite- and infection-specific associations.

\section{Acknowledgments}

Funding: This work was supported by Institute for Information \& communications Technology Promotion (IITP) grant funded by the Korea government (MSIT) (2018-0-00861, Intelligent SW Technology Development for Medical Data Analysis).

\section{Footnote}

Reporting Checklist: The authors have completed the PRISMA 2009 reporting checklist. Available at http:// dx.doi.org/10.21037/jgo-20-199

Peer Review File: Available at http://dx.doi.org/10.21037/ jgo-20-199

Conflicts of Interest: All authors have completed the ICMJE uniform disclosure form (available at http://dx.doi. org/10.21037/jgo-20-199). The authors have no conflicts of interest to declare.

Ethical Statement: The authors are accountable for all aspects of the work in ensuring that questions related to the accuracy or integrity of any part of the work are appropriately investigated and resolved.

Open Access Statement: This is an Open Access article distributed in accordance with the Creative Commons Attribution-NonCommercial-NoDerivs 4.0 International License (CC BY-NC-ND 4.0), which permits the noncommercial replication and distribution of the article with the strict proviso that no changes or edits are made and the original work is properly cited (including links to both the formal publication through the relevant DOI and the license). See: https://creativecommons.org/licenses/by-nc-nd/4.0/.

\section{References}

1. Bray F, Ferlay J, Soerjomataram I, et al. Global cancer statistics 2018: GLOBOCAN estimates of incidence and mortality worldwide for 36 cancers in 185 countries. CA Cancer J Clin 2018;68:394-424.

2. Karimi P, Islami F, Anandasabapathy S, et al. Gastric cancer: descriptive epidemiology, risk factors, screening, and prevention. Cancer Epidemiol Biomarkers Prev 2014;23:700-13.

3. Batty GD, Shipley MJ, Gunnell D, et al. Height, wealth, and health: an overview with new data from three longitudinal studies. Econ Hum Biol 2009;7:137-52.

4. Emerging Risk Factors C. Adult height and the risk of cause-specific death and vascular morbidity in 1 million people: individual participant meta-analysis. Int $\mathrm{J}$ Epidemiol 2012;41:1419-33.

5. Stefan N, Haring HU, Hu FB, et al. Divergent associations of height with cardiometabolic disease and cancer: epidemiology, pathophysiology, and global implications. Lancet Diabetes Endocrinol 2016;4:457-67.

6. Stroup DF, Berlin JA, Morton SC, et al. Meta-analysis of observational studies in epidemiology: a proposal for reporting. Meta-analysis Of Observational Studies in Epidemiology (MOOSE) group. JAMA 2000;283:2008-12.

7. Stang A. Critical evaluation of the Newcastle-Ottawa scale for the assessment of the quality of nonrandomized studies in meta-analyses. Eur J Epidemiol 2010;25:603-5.

8. Orsini N, Li R, Wolk A, et al. Meta-analysis for linear and nonlinear dose-response relations: examples, an evaluation of approximations, and software. Am J Epidemiol 2012;175:66-73.

9. Greenland S, Longnecker MP. Methods for trend estimation from summarized dose-response data, with applications to meta-analysis. Am J Epidemiol 1992;135:1301-9.

10. Higgins JP, Thompson SG, Deeks JJ, et al. Measuring inconsistency in meta-analyses. BMJ 2003;327:557-60.

11. Patsopoulos NA, Evangelou E, Ioannidis JP. Sensitivity of between-study heterogeneity in meta-analysis: proposed metrics and empirical evaluation. Int J Epidemiol 2008;37:1148-57.

12. Choi YJ, Lee DH, Han KD, et al. Adult height in relation to risk of cancer in a cohort of 22,809,722 Korean adults. Br J Cancer 2019;120:668-74.

13. Wiren S, Haggstrom C, Ulmer H, et al. Pooled cohort study on height and risk of cancer and cancer death. Cancer Causes Control 2014;25:151-9.

14. Kabat GC, Kim MY, Hollenbeck AR, et al. Attained height, sex, and risk of cancer at different anatomic sites in the NIH-AARP diet and health study. Cancer Causes Control 2014;25:1697-706.

15. Kabat GC, Anderson ML, Heo M, et al. Adult stature and risk of cancer at different anatomic sites in a cohort of postmenopausal women. Cancer Epidemiol Biomarkers 
Prev 2013;22:1353-63.

16. Green J, Cairns BJ, Casabonne D, et al. Height and cancer incidence in the Million Women Study: prospective cohort, and meta-analysis of prospective studies of height and total cancer risk. Lancet Oncol 2011;12:785-94.

17. Minami Y, Tochigi T, Kawamura S, et al. Height, urbanborn and prostate cancer risk in Japanese men. Jpn J Clin Oncol 2008;38:205-13.

18. Merry AH, Schouten LJ, Goldbohm RA, et al. Body mass index, height and risk of adenocarcinoma of the oesophagus and gastric cardia: a prospective cohort study. Gut 2007;56:1503-11.

19. MacInnis RJ, English DR, Hopper JL, et al. Body size and composition and the risk of gastric and oesophageal adenocarcinoma. Int J Cancer 2006;118:2628-31.

20. Gunnell D, May M, Ben-Shlomo Y, et al. Height, leg length, and cancer: the Caerphilly Study. Nutr Cancer 2003;47:34-9.

21. Ji BT, Chow WH, Yang G, et al. Body mass index and the risk of cancers of the gastric cardia and distal stomach in Shanghai, China. Cancer Epidemiol Biomarkers Prev 1997;6:481-5.

22. Hansson LE, Baron J, Nyren O, et al. Early-life risk indicators of gastric cancer. A population-based casecontrol study in Sweden. Int J Cancer 1994;57:32-7.

23. Kim MA, Lee HS, Yang HK, et al. Clinicopathologic and protein expression differences between cardia carcinoma and noncardia carcinoma of the stomach. Cancer 2005;103:1439-46.

24. Graham DY. Helicobacter pylori update: gastric cancer, reliable therapy, and possible benefits. Gastroenterology 2015;148:719-31.e3.

25. Anderson WF, Camargo MC, Fraumeni JF Jr, et al. Agespecific trends in incidence of noncardia gastric cancer in

Cite this article as: Seo MS, Park DK, Hwang IC, Shim JY, Ahn HY. Adult height is not associated with the risk of stomach cancer in a meta-analysis. J Gastrointest Oncol 2020;11(4):708714. doi: 10.21037/jgo-20-199
US adults. JAMA 2010;303:1723-8.

26. Chen Y, Liu L, Wang X, et al. Body mass index and risk of gastric cancer: a meta-analysis of a population with more than ten million from 24 prospective studies. Cancer Epidemiol Biomarkers Prev 2013;22:1395-408.

27. Venerito M, Vasapolli R, Rokkas T, et al. Gastric cancer: epidemiology, prevention, and therapy. Helicobacter 2018;23 Suppl 1:e12518.

28. Goodman KJ, Correa P, Mera R, et al. Effect of Helicobacter pylori infection on growth velocity of schoolage Andean children. Epidemiology 2011;22:118-26.

29. Moayyedi P, Forman D, Duffett S, et al. Association between Helicobacter pylori infection and adult height. Eur J Epidemiol 2005;20:455-65.

30. Camargo MC, Freedman ND, Hollenbeck AR, et al. Height, weight, and body mass index associations with gastric cancer subsites. Gastric Cancer 2014;17:463-8.

31. Clayton PE, Banerjee I, Murray PG, et al. Growth hormone, the insulin-like growth factor axis, insulin and cancer risk. Nat Rev Endocrinol 2011;7:11-24.

32. Renehan AG, Zwahlen M, Minder C, et al. Insulin-like growth factor (IGF)-I, IGF binding protein-3, and cancer risk: systematic review and meta-regression analysis. Lancet 2004;363:1346-53.

33. Albanes D, Winick M. Are cell number and cell proliferation risk factors for cancer? J Natl Cancer Inst 1988;80:772-4.

34. Trichopoulos D, Lipworth L. Is cancer causation simpler than we thought, but more intractable? Epidemiology 1995;6:347-9.

35. Cairns BJ, Liu B, Clennell S, et al. Lifetime body size and reproductive factors: comparisons of data recorded prospectively with self reports in middle age. BMC Med Res Methodol 2011;11:7. 